Res Publica Revista de Historia de las Ideas Políticas

ISSN: $1131-558 \mathrm{X}$

\title{
Crisis y restauración del liberalismo. El tránsito por la Revista de Estudios Políticos en sus diez primeros años (1941-1950)
}

José Luis Mora García*

Recibido: 19-03-2021 / Aceptado: 20-05-2021

Resumen. El artículo versa sobre el proceso que siguió la Revista de Estudios Politicos (1941), creada como órgano de difusión del Instituto del mismo nombre, fundado dos años antes, a la finalización de la guerra civil. En ella escribieron intelectuales de la órbita orteguiana que hicieron un recorrido a lo largo de estos diez primeros años desde la quiebra del liberalismo político a la puesta de las primeras bases para su reconstrucción. Al fondo se alude al novelista Benito Pérez Galdós, a la finalización del año de su centenario, autor de la emblemática obra Electra en cuyo estreno y reestrenos ha sido considerada como un símbolo de la lucha por la libertad de conciencia.

Palabras clave: liberalismo; conciencia; España; Europa; Hispanoamérica.

[en] From the Crisis of Liberalism to its Restoration: An Analysis of the First Ten Years of the Revista de Estudios Políticos (1941-1950)

Abstract. This article deals with the process followed by the Revista de Estudios Politicos (1941), created as an organ of dissemination of the Institute of the same name, founded two years earlier, at the end of the civil war. This journal featured work by intellectuals from the Ortegan school of philosophy who made a journey through these first ten years of the journal's existence from the bankruptcy of political liberalism to the laying of the first foundations for its reconstruction. Reference is also made to the novelist Benito Pérez Galdós, at the end of his centenary year, as the author of the emblematic work Electra whose premiere and reruns have been seen as a symbol of the struggle for freedom of conscience.

Keywords: Liberalism; Conscience; Spain; Europe; Latin America.

Sumario. Bibliografía.

Cómo citar: Mora García, J. L. (2021). Crisis y restauración del liberalismo. El tránsito por la Revista de Estudios Políticos en sus diez primeros años (1941-1950). Res Publica. Revista de Historia de las Ideas Politicas, 24(2), 211-222.

Resulta ilustrativo, cuando menos, abordar el papel que desempeñó la Revista de Estudios Políticos aun con el recuerdo del reestreno de Electra, la obra que Benito Pérez Galdós estrenara el 30 de enero de 1901, en el mismo teatro, "El Español". Fue repuesta brillantemente por Francisco Nieva en 2010 y ha sido recuperada ahora en forma de monólogo en la Casa Museo de Las Palmas al finalizar el año del centenario del escritor canario ${ }^{1}$. Hemos podido recordar el entusiasta artículo que bajo el título "El público desde adentro" ofrecía al día siguiente en el diario El País (31 de enero de 1901) un casi enardecido Ramiro de Maeztu. "¡Oh noche histórica la del 29 de enero!... Yo os conjuro a todos, jóvenes de Madrid, de Barcelona, de América, de Europa, para que os agrupéis en derredor del hombre que todo lo tenía y todo lo ha arriesgado por una idea, que es vuestra idea, la de todos los hombres merecedores de la vida. ¿Lo habéis visto?... El hombre de la ciencia, del cálculo y de la exactitud, la inteligencia fría e impasible, tiene un sueño superior; Electra -y ese hombre es Galdós- y Electra somos nosotros -los hombres y la tierra-".

* Universidad Autónoma de Madrid jose.mora@uam.es

1 El año 2020 se ha recordado el centenario del fallecimiento del novelista canario. Ha sido la ocasión que ha permitido asistir a representaciones totales o parciales de algunas de sus obras. La Casa Museo desde Las Palmas, como eco de las celebraciones, trasmitió un excelente monólogo a partir de textos de Electra el 18 de marzo de 2021 por la compañía "La República” bajo la dirección de Nacho Cabrera. 
A Maeztu acompañaba un igualmente entusiasmado Baroja y un más reticente Azorín a quien reconvino el propio Maeztu en otro artículo publicado en el Madrid Cómico el 16 de febrero en el que le recordaba que en "Electra hay un dilema; o el trabajo o el convento. Galdós ha optado por el trabajo; nosotros con él. ¿Cómo íbamos a prescindir de nuestro amor hacia esa pobre España tan inculta, tan grosera, tan fanática? - palabras de usted-".

Unos años después, Pérez Galdós formaría parte de la coalición republicano socialista que llevaría a Pablo Iglesias, fundador del PSOE, a ser diputado. Por su parte, hacía ya algunos años que Maeztu había comenzado su estancia en Inglaterra, aunque volviera para dar conferencias en los años en que se mantuvo su proximidad con Ortega quien, como es sabido, le dedicó la primera edición de sus "Meditaciones". Aún habrían de pasar más años para la fundación de "Acción Española" y la Defensa de la Hispanidad, gestada probablemente a su paso por Argentina en los mismos años en que Ortega estuvo allí por segunda vez con resultados bastante diferentes.

Traigo a colación aquí estas referencias por dos motivos: el primero resulta de comprobar el papel conferido por Galdós a la historia tal como mostró en la elaboración de cuarenta y cinco Episodios Nacionales dedicadas al siglo XIX español, verdadera protagonista de la obra, más que la propia niña-mujer, Electra, de nombre con resonancias de la tragedia clásica cuyo tema fue recreado por los grandes de la literatura griega y que ahora lo era en el marco de lo que significaba el descubrimiento de la electricidad. Es verdad que, sin remisión a la historia, no se podría haber aclarado el drama que la obra plantea. Hoy ese lugar lo hubiera ocupado, en cambio, un análisis de ADN. La historia sería, igualmente, protagonista de las dos últimas series de Episodios, incluido el titulado lúcidamente "La primera República" y el final del último, Cánovas, que acaba con una profecía de la diosa Clío y su llamamiento a los liberales, aquellos que habían protagonizado la Revolución de 1868 y la Primera República, para que sepan cómo traer la definitiva república, proclama a la que me referiré como final de estas consideraciones.

El segundo motivo de recordar aquí esta obra, a propósito de la recuperación del pensamiento político y la naturaleza de la misma en relación con su evolución en las últimas décadas, tiene que ver con la reacción del público en la España de 2010, por consiguiente en nuestro tiempo, a la finalización de la representación y que aún recuerdo. Aparte de las excelentes bondades estéticas de la adaptación de Francisco Nieva, siguen llamando la atención, por igual, los fuertes aplausos al argumento que la obra plantea, al tiempo que esos aplausos escenificaban un estado de tranquilidad, alejado de las reacciones que produjo el primitivo estreno. La última reposición ha sido más silenciosa, pero mantiene la misma fuerza. La historia también, pues, de la propia obra de teatro, ese género que con razón Unamuno señalaba que había servido en tantas ocasiones para que España se salvara y que a Maeztu tanto pareció entusiasmarle.
Un siglo de nuestra historia, entre la primera representación en la misma plaza de Santa Ana, con actores reales de las primeras décadas del siglo XX mientras nacían quienes habrían de protagonizar las siguientes décadas, actores reales igualmente de la España de Franco y la transición a la democracia, herederos que seguramente tomaron conciencia de la propia historia y trataron de ahormarla. Y con nosotros, actores igualmente reales, herederos de toda esta historia, de un siglo entero sin duda, pero, de manera más directa, de ese periodo referido a la "recuperación" o "restauración", dicho con las palabras que Ortega usó en La rebelión de las masas. Correspondería el papel asignado a la revista al tercer estadio que toda revolución debe llevar a cabo tras la templanza del primero y la radicalidad del segundo. Precisamente, es el que corresponde al refrán castellano de "dar trigo".

Mas, no olvidemos que solo hay que restaurar lo que se ha destruido. Ya sé que la respuesta es obvia. Había sucedido ni más ni menos que una guerra civil por medio. Pero si se atiende a los miembros que comienzan a formar parte de la Revista de Estudios Políticos: falangistas, una parte de ellos de formación orteguiana; liberales que lo habían sido durante la República y que ni militaron ni estuvieron próximos a ningún movimiento político pero que no se exiliaron; los provenientes de la Asociación Católica Nacional de Propagandistas (ACNP); y los miembros de "Acción Española", tenemos un cuadro verdaderamente complejo de personas que habían estado próximas, que luego se habían distanciado y que volvían a encontrarse. Si hacemos caso al diagnóstico realizado por Salvador Giner y el comentario que hace del Pensamiento Español en la era de Franco (1939-1975) en Revisión de Elías Díaz, sus libros y sus críticos ${ }^{2}$ publicado precisamente en el Centro de Estudios Políticos y Constitucionales ${ }^{3}$, los sectores más integristas desde un punto de vista religioso se refugiarían en Arbor pues sería a partir de 1945 cuando se podría hablar de nacionalcatolicismo.

Esta coexistencia, convivencia o cualquiera que fuera el grado de relación entre estos intelectuales que se llevó a cabo en la Revista de Estudios Políticos, parece ser vista como clave para explicar que el Régimen de Franco sobreviviera a los fascismos europeos, dotándose de nuevas formas de legitimación primero y de funcionamiento después y, seguramente, así fue. Es el paso del falangismo al liberalismo que supondría, para algunos de ellos -los más mayores-, recuperar viejas raíces como le sucede al propio Laín, inicialmente becado por la JAE o, en general, les pasa a los intelectuales del círculo de Ortega y Gasset. Mas estudiar todo ese proceso que constituye la búsqueda de legitimación hasta lo que puede considerarse apuesta por el "funcionalismo" que se desarrolló desde los años cincuenta y, sobre todo, los sesenta, requeriría un estudio más detallado del que se

E. Díaz, Pensamiento Español en la era de Franco (1939-1975), Madrid, Tecnos, 1992.

S. Giner, "La reconstrucción cívica de la razón (Reflexiones sobre la interpretación de Elías Díaz en su Pensamiento español en la era de Franco", Revisión de Elías Díaz, sus libros y sus críticos, L. Hierro; F. Laporta, y A. Ruiz Miguel, (eds.), Madrid, Centro de Estudios Políticos y Constitucionales, 2007, pp. 157-162. 
puede ofrecer aquí ya que nos limitamos ahora a la consulta de los diez primeros años de la revista. Aun así, incluye las primeras firmas de Aranguren y del propio Tierno Galván que jugarían un papel tan importante en las siguientes décadas, y en esa primera década quedan ya apuntadas las bases de lo que va a suponer el paso de la Filosofía de la Historia o de la Filosofía del Derecho a la Sociología, es decir, la apuesta por las nuevas ciencias sociales que van arrumbando a la vieja escolástica de manera suave y obligaron a la filosofía a competir con la ciencia o a hacerse ella misma científica. Ya de los años cincuenta son las primeras cátedras de Gómez Arboleya y Salvador Lisarrague, como han historiado Salustiano del Campo en su Historia de la Sociología Española y Salvador Giner en "Spanish Sociology under Franco"s. De ahí hasta La comunicación humana de Aranguren ${ }^{6}$ o Escuela, ideología y clases sociales en España de Carlos Lerena ${ }^{7}$, como exponentes de la recepción de la sociología francesa en los años setenta, un largo periplo que necesitaría, a su vez, un más largo desarrollo del que aquí es posible ofrecer. Al cumplirse en 2020 los cincuenta años (1970) de la LGE que firmara Villar Palasí, para quienes hemos desarrollado nuestra carrera profesional en este periodo y, además, como es mi caso, en una Escuela de Formación de Profesores durante una parte de mi vida, hemos tenido una plataforma bastante privilegiada para saber cómo se han ido produciendo las cosas durante el tiempo de los finales del franquismo y los primeros años de la instauración de la democracia.

Habrían quedado fuera de esta restauración, literalmente fuera, es decir, expulsados del país, los liberales directamente vinculados a la ILE o, incluso, los que sin pertenecer directamente a ella podían considerarse próximos o muy próximos por formación, por intereses o por dedicarse directamente a la enseñanza. Este apartado ha sido espléndidamente estudiado por Elías Díaz en su De la Institución a la Constitución en el capítulo segundo y a él me remito ${ }^{8}$. Ahí ofrece la larga lista de quienes hubieron de exiliarse. Los epígrafes "La destrucción de la razón en la España de posguerra", "Los sin patria y los sin Dios, de la Libre Institución" y "Fascismo católico contra libertad política e intelectual" son los marcos bajo los que desgrana los improperios que recibieron los institucionistas quienes, para el Régimen, encarnaban los efectos nocivos atribuidos a la República. Ahí puede leerse una retahíla de epítetos que el tiempo y la investigación han dejado a la intemperie.

Por cierto, no es casual que Elías Díaz, junto con José Luis Abellán, fueran en años tempranos de los muy pocos que, en el ámbito de la Filosofía, escribieran o promovieran investigaciones sobre los intelectuales de la tradición republicana española - de la primera República a la segunda- con su edición de Gumersindo Azcárate o de Fernando de los Ríos o las tesis sobre Giner, Besteiro, el propio de los Ríos, etc.; o la Filosofía Es-

Barcelona, Ariel, 2001.

S. Giner y L. Moreno (eds.), Sociology in Spain, Madrid, CSIC, 1990.

Madrid, Tecnos, 1986.

Barcelona, Ariel, 1976

E. Díaz, De la Institución a la Constitución. Política y cultura en la España del siglo XX, Madrid, Trotta, 2009, pp. 49-79. pañola en América (1936-1966) de José Luis Abellán9; o ya, en los setenta, la colección publicada en Taurus y coordinada por el propio Abellán.. Sin olvidar, claro está, la importante figura de Eloy Terrón, merecedor del trabajo que Jerez Mir está haciendo por reivindicar su figura. Habría que llegar, ya a comienzo de los setenta, a la tesis, elaborada por Heredia y dirigida por Cruz Hernández, sobre Nicolás Salmerón, para encontrar un nexo más próximo que está en el espíritu fundacional del Seminario de Historia de la Filosofía Española e Iberoamericana de la Universidad de Salamanca, por paradójico que a algunos les pudiera parecer, hace más de cuarenta años. Mucho más tímida fue la aproximación de Aranguren o Marías. No faltó de manera más decidida, en otros ámbitos de la cultura como fue la revista Ínsula, pero esa recuperación pertenece más al ámbito de los escritores que de los propiamente filósofos. En fin, quede dicho esto, así y de paso y a falta de mayores precisiones, mas sabiendo que no ha sido este un asunto baladí, ni para la evolución del país en general ni para la propia institucionalización de la filosofía en España durante las últimas décadas. Desarrollar este apartado de manera más extensa y completa sería tema de otro estudio más pormenorizado, pero no deja de estar vinculada la reconstrucción de la filosofía en España con la naturaleza de la restauración del pensamiento político. Concretamente tiene que ver con las dificultades, por decirlo ahora de manera suave, que la filosofía española ha tenido para recuperar $\mathrm{y}$, a partir de ahí, comprenderse como formando parte de una tradición propia. Cuando lo expreso en estos términos no me refiero a la filosofía como si fuera parecida a cuando uno pide tomates en el mercado y le preguntan si los quiere "del terreno" o de importación, sino a todo un planteamiento que incluiría una aproximación a cómo ha sido tratada la historia de España y cómo lo han sido las de otros países de Europa, así como de los países de Iberoamérica. Y, por supuesto, a cómo han sido tratadas todas estas recíprocas relaciones.

El Instituto de Estudios Políticos hizo la propuesta que le convenía para la legitimación de un Estado fascista en términos epistemológicos y políticos y condicionó, por consiguiente, las propuestas que se hicieron desde fuera, a la contra, diría que casi lógicamente, pero en ocasiones desde corrientes o autores que se han desvanecido con rapidez por no tener raíz alguna como hemos ido viendo en estos últimos años. Aparte índices de impacto oficializados, puede hacerse un seguimiento y comprobar qué libros se cotizan en los circuitos de librerías de libro viejo para comprobar lo que estoy diciendo.

Así pues, el marco intelectual, creado por la Revista de Estudios Políticos, y seguramente por Escorial, está en la base, para bien y para regular, de casi todo lo que ha pasado en el ámbito de las Ciencias Políticas. De ahí salió la propia Facultad de la Universidad Complutense y de ella sus intelectuales más reconocidos. También, de las consecuencias que tuvo para la propia constitución del pensamiento que siguió un periplo complejo pues, si bien se inició con la finalidad de la legitimación, derivó

Madrid, Ediciones Guadarrama con Seminario de Ediciones, 1966 
bastante tempranamente, hasta agudizarse luego, en la funcionalización interna del Estado, lo que condicionó o hasta obligó, aunque no lo haya parecido siempre, a que el pensamiento de la izquierda también buscara formas de legitimación democrática que no pertenecían a la propia historia de España, es decir, no a la tradición republicana española sino a otras de procedencia externa. Por ejemplo, se apoyó, en términos ideológicos, en el marxismo francés o italiano; en términos políticos, en la socialdemocracia alemana o sueca, etc.; u optó por modelos funcionalistas de origen americano basados en las teorías del capital humano. Las clases medias españolas que hicieron la primera y la segunda transición son hijas de esta herencia y todo esto ha condicionado el debate político hasta nuestro tiempo entre quienes se remiten a esta herencia evolucionada del franquismo o quienes piensan que debe recuperarse la tradición republicana de carácter institucionista, la que quedó fuera del juego político tras la guerra, a diferencia de otras variantes del liberalismo que sobrevivieron dentro.

Esto explica que haya amplios sectores que siguen pensando que, después de todo, el franquismo no fue tan malo en términos de funcionamiento de Estado cuando realmente de lo que se habla no es de pantanos, de la misma manera que, cuando se habla de cualquier otro régimen fascista, bolchevique o simplemente autoritario, no se habla de calidad de estos servicios, sino antes que nada, de la legitimidad política del ejercicio del poder. Y saber de dónde se alcanza la legitimidad que ahora se vive. A algo de esto se refería María Zambrano en su "Carta sobre exilio" de 1961 que conviene leer despacio para saber cuál era la situación entonces y la que hemos heredado.

A la recepción del exilio filosófico dediqué mi intervención en el $70^{\circ}$ aniversario de 1939 celebrado en la ciudad de México en $2009^{10}$ y allí me refería a las dificultades que han existido y que van dejando paso a un periodo lento de normalización, que aún habrá de durar, en la articulación con la que fue resistencia interior al franquismo. De alguna tensión que, a este propósito se generó en el marco de aquel congreso, es testigo José Luis Abellán y él recordará algunas intervenciones que tuvimos en el mismo. En todo caso es síntoma de que algunas cicatrices no están bien suturadas.

Y no lo están porque, con sus diferencias, todas esas formas u orientaciones políticas se sentían próximas antes de la guerra. Había muchos intelectuales de distintas profesiones, incluida la enseñanza, que admiraban por igual a Unamuno y a Ortega; que dieron un duro cada mes para el mantenimiento de la familia del ex Rector salmantino durante su destierro y que estaban suscritos a Revista de Occidente y leían a Ortega como autoridad intelectual de referencia y leían, también, a Pérez Galdós y no por eso dejaban de reconocer el significado del historiador católico como llama María Zambrano a Menéndez Pelayo a quien cita como autoridad. Había per-

10 J.L. Mora García, "La recepción del exilio filosófico en España. Una aproximación”, A. Pavón Romero; Ramírez C. I. Ramírez González y A. Velasco Gómez, Estudios y testimonios sobre el exilio español en México. Una visión sobre su presencia en las Humanidades, México, CONACYT, 2016, pp. 129-166. sonas de un amplio abanico ideológico a quienes unía la apuesta por el conocimiento y la cultura. Era la cultura la base de la sociedad que deseaban construir y todo ello en torno a una idea de España que básicamente compartían. Sobre todo, es que querían a España. Bastaría leer muchos textos desde la generación de 1868 hasta la de 1929 para corroborar esto. ¿Por qué se fracturó esta unidad? ¿Sobre qué bases epistemológicas se produjo? ¿Por qué causas, intelectuales de formación liberal, terminaron apoyando expresamente un golpe de Estado?

Son estas preguntas no fáciles de responder $\mathrm{y}$, sin embargo, no solo sirven para dar cuenta de la fractura de la nación, cuando falló de manera dramática la unidad que existía sobre la base de la cultura que fue sustituida por las armas, -cuando la política y las armas ocuparon el espacio que había correspondido a la cultura: periódicos, universidades populares, revistas, enseñanza, la nueva universidad, etc. etc.- sino de cómo habría de producirse la posterior "restauración" tras la guerra que interrumpió muchas cosas, modificó otras, pervirtió otras tantas, pero no pudo impedir que quienes sobrevivieron a la guerra siguieran viviendo después, es decir, que se produjeran reencuentros y que las ideas que poseían se entrecruzaran. Sí realmente sucedió que una parte importantísima de la intelectualidad tuviera que exiliarse y no regresara, o lo hiciera mucho después y que, por lo que concierne al ámbito filosófico, las relaciones fueran casi nulas o muy débiles hasta mucho más adelante, a diferencia del exilio literario cuya influencia nunca se interrumpió del todo. Claro que era en el pensamiento político donde ahora se dilucidaba la legitimidad del nuevo Estado y no es que la literatura fuera inocua, pero podía controlarse mejor. Y esto es lo que sucedió en el Instituto de Estudios Políticos en torno a la figura y el pensamiento que ocupó el centro de todo el debate, antes de la guerra y que lo tendrá después: José Ortega y Gasset.

El discurso unitario se rompió definitivamente hacia el final del primer bienio de la República. Antes, había habido tensiones. Por ejemplo, cuando los jóvenes le presentaron a Marañón el texto fundacional de la Liga para la Educación Social de cuya reacción quedaron más bien descontentos. Y, por supuesto, los encuentros/desencuentros de María Zambrano con Ortega tal como nos han llegado a través de las cartas que publicó Revista de Occidente ${ }^{11}$ y los propios testimonios de Zambrano como los ha descrito Jesús Moreno en el extenso prólogo a Horizontes del Liberalismo ${ }^{12}$. Ciertamente, en la "Proclama de la Generación del 29" que figura a modo de prólogo del libro Castidad, Impulso, Deseo del entonces joven médico Carlos Díez Fernández ${ }^{13}$, que lo era de María Zambrano, casado en enero de 1931 con Araceli Zambrano, un intelectual de mucho peso cuya influencia no ha sido suficientemente tenida en cuenta, se dice textualmente: "Los temas sociales, políticos, religiosos, morales, jurídicos, cinemáticos, deportivos y literarios

11 M. Zambrano, "María Zambrano: Tres cartas de juventud a Ortega y Gasset", Revista de Occidente, mayo 1991, pp. 7-26.

12 M. Zambrano, Horizonte del liberalismo, Edición y estudio introductorio a cargo de Jesús Moreno, Madrid, Morata, 1996.

13 Madrid, Javier Morata editor, 1930. 
van a ser expuestos por auténticos jóvenes en la forma y contenido renovadores con que ellos los conciben, plantean y resuelven". El texto de cuatro páginas se cerraba con las palabras puestas en mayúscula: "VERDAD Y CONVICCIÓN", fechado a 30 de mayo de $1930{ }^{14}$. Poco después la propia Zambrano publicaría en esta misma colección, dentro la serie "Nueva generación", Horizonte del liberalismo, y Nuevos Horizontes ${ }^{15}$ fue el título que los amigos de su padre pusieron a la recopilación de sus escritos en 1935. Por cierto, aquí la figura de Pablo de Andrés Cobos, interlocutor luego de tantos exiliados, ya se mostraba clave por razones que necesitarían también alguna aclaración un poco más larga.

Lo cierto es que la repetición de lo nuevo venía a convertir a Ortega en viejo como él había hecho con la política de la Restauración, pero, aun así, creo que la ruptura se pospuso al menos un par de años pues, tanto el artículo de Zambrano, "Castilla a solas consigo misma", publicado en Segovia Republicana el 29 de julio de 1931 como, sobre todo, el famoso manifiesto "Un movimiento político de juventud. Frente Español" hecho público el 7 de marzo de 1932, en el diario Luz, estudiado con detalle por Elorza y por Jesús Moreno, mantenían la influencia orteguiana. Fue el canto del cisne de esa unidad cuyas claves habría que analizar algo más matizadamente y no simplemente señalar que era reaccionario pues de esto se dieron cuenta inmediatamente después. Y aquí es donde algunos orteguianos ya iniciaron la deriva hacia la construcción de un Estado totalitario, fascista si se quiere, por cuanto buscaría la imposición cerrada, piramidal, desde una concepción monolítica del Estado. Que fuera Alfonso García Valdecasas o la propia Zambrano quienes hicieran la redacción final es menos relevante. Junto a Zambrano firmaban Eliseo del Moral, Salvador Lissarrague, José Antonio Maravall, Antonio Riaño, José Ramón Santeiro y Abraham Vázquez, algunos de cuyos nombres encontraremos entre los más relevantes de la Revista de Estudios Políticos, sobre todo los de Maravall y Lisarrague, junto al propio García Valdecasas. La rápida disolución del movimiento iniciaba un distanciamiento, ya inevitable. Zambrano, como es sabido, emprendió el camino del exilio en 1939 como otros muchos. Era la consumación de una fractura cuya sutura está costando mucho restaurar, ya no en el plano de la legalidad democrática, conseguida hace tiempo, sino en otro algo más profundo y difícil de detectar. Este "algo" no pertenece al ámbito de la legitimación ni siquiera al ámbito social sino a las relaciones que condicionan la convivencia cotidiana.

Por esos años, por cierto, Dionisio Ridruejo, por las mismas calles de Segovia que había compartido brevemente con los Zambrano como estudiante de los Maristas en 1922, pero ahora más continuadamente en el ambiente que marcaba la señora Fromkes y con la inspiración de su amada señora Aurea, iniciaba un camino marcado por la seducción estética del orden hacia la Falange. Zambrano, por su parte, aun tuvo tiempo de escri-

\footnotetext{
Ibidem, p. 10.

P. de Andrés Cobos y otros (eds.), Nuevos Horizontes, Segovia, Imp. De Carlos Martín, 1935.
}

bir "Los intelectuales y el drama de España" y la carta a Marañón publicada en La Nación de Buenos Aires.

Lo que hicieron Ramiro de Maeztu, Ramiro Ledesma y la propia deriva de los intelectuales de la Generación del 14, Marañón, Ortega y Pérez de Ayala, es conocida a través de las cartas publicadas, los estudios realizados, etc. y no es necesario incidir aquí mucho más.

Lo cierto es que si España invertebrada y La rebelión de las masas terminaron por ser los catecismos para una lectura fascista, y ese Ortega es reivindicado una y otra vez en todos los artículos de la primera época de la Revista de Estudios Políticos, esto nos lleva obligatoriamente a pensar en la fragilidad que la filosofía padece en ciertas situaciones o, por el contrario, en los gérmenes de la filosofía social de los intelectuales del 14 que, aun siendo de raíz liberal, fue leída en clave fascista.

"Uno y otro - bolchevismo y fascismo- son dos seudoalboradas; no traen mañana de mañana sino la de un arcaico día, ya usado una y muchas veces; son primitivismo. Y eso serán todos los movimientos que recaigan en la simplicidad de entablar un pugilato con tal o cual porción del pasado, en vez de proceder a su digestión", señala Ortega en el segundo de los ensayos citados ${ }^{16}$. También en el "Epílogo para ingleses" quedaba claro su rechazo a la teoría de los caracteres generales: "Mientras se crea -afirma- que un pueblo posee un "carácter" previo y que su historia es una emanación de este carácter, no habrá manera ni siquiera de iniciar la conversación" 17 . Bien es verdad que dice otras muchas cosas no siempre compatibles entre sí y seguramente aquí está la clave de por qué fue leído en clave fascista. Lo mismo podemos pensar, si nos referimos a su actitud personal, pues sabemos, por el epistolario con Marañón, cuál fue ésta durante la guerra y después. Ya Gregorio Morán, en su libro que tanto molestó en algunas instancias ${ }^{18}$, debido a algunos excesos que ahí se contienen pero que, no por ello dejaba de poner cosas en claro, nos había descubierto algunas claves que no pueden pasar inadvertidas acerca de la posición que adoptaron los intelectuales de la generación de las vanguardias, y una parte importante de sus círculos, en relación con el golpe de Estado. Lo que es más difícil de dilucidar es por qué se produjo este corrimiento. Antonio Martín Puerta en su libro Ortega y Unamuno en la España de Franco sostiene que "se trataba sin duda de personas de mentalidad liberal, que así siguieron pensando toda su vida; simplemente huyeron de la revolución y de las amenazas que vivieron en la zona republicana e intentaron sobrevivir, con las menores molestias y compromisos posibles, dentro de otro sistema que más bien les apasionaba poco, pero que les permitió seguir adelante"19. Señalar que se sintieron obligados es una exculpación que puede sostenerse desde un punto de vista personal, mas no intelectual ni políticamente. Precisamente, esta actitud era la que criticó

\footnotetext{
6 Madrid, Revista de Occidente, 1983, pp. 115-116. Primera edición, 1930.

17 Ibidem, 203.

18 G. Morán, El maestro en el erial. Ortega y Gasset y la cultura del franquismo, Barcelona, Tusquets, 1998.

19 A. Martín Puerta, Ortega y Unamuno en la España de Franco. El debate intelectual durante los años cuarenta y cincuenta, Madrid, Encuentro, 2009, pp. 39-40.
} 
con tanta dureza Zambrano. Probablemente, este juicio valga para Marañón, Pérez de Ayala y Ortega y menos para otros que sí estuvieron convencidos, durante un tiempo, de que el fascismo era necesario. Desde luego Ridruejo, Tovar y Laín pertenecerán al segundo grupo con algún matiz en el caso de este último.

Como años después escribiría desde Inglaterra, y en inglés, José Castillejo, tras analizar el periodo de la República, en tono mucho más crítico para lo habitual desde los ámbitos institucionistas, "la opinión pública respaldó al dictador en los primeros años, quizás porque todos creían que la dictadura iba a ser un breve paréntesis de reajuste" ${ }^{20}$. Y este diagnóstico fue, al parecer, compartido por los mismos a quienes el propio Castillejo señala como defensores de un "gobierno de catedráticos".

Cuando el P. Fraile publique en Ciencia Tomista su artículo "¡La guerra ha terminado!" cerrándolo con "la España cuyo espíritu hemos vuelto a recobrar y que ya nada ni nadie nos podrá jamás volver a arrebatar" ${ }^{21}$, comenzaba otra tarea: la legitimación del Estado que había de apoyar esa "España recobrada", expresión que hizo suya la retórica de los vencedores. Habían sido expulsados muchos y quedaban dentro - me refiero ahora a intelectuales- los que habían apostado por el pronunciamiento - palabra textual que emplea Juan Gascón Hernández ya en un artículo de 1945 titulado "Caracteres y funciones de la presidencia de las Cortes españolas"- y los liberales cuyo grado de satisfacción puede estar cerca de las palabras de la carta de Ortega a Marañón de 30 de marzo de 1939 en los términos de "alborozo y satisfacción" o, seguramente, algo menos.

Esta función de legitimación fue asignada al Instituto de Estudios Políticos, creado ya 1939, y su órgano de expresión, la revista del mismo nombre, que nació en enero de 1941. Como señala Nicolás Sesma Landrín, autor de un muy buen trabajo introductorio a la Antología de la "Revista de Estudios Políticos" "22, esta "era, en gran parte, heredera de las publicaciones del naciente movimiento fascista español de preguerra, que aspiraba a servirse de ellas como elemento de presencia pública y plataforma desde la que atraer la colaboración de prestigiosos intelectuales, propósito que contrastaba con el carácter anti-intelectualista tanto de su militancia de base como de su propia retórica" ${ }^{23}$. Creo que esto fue así. Si durante el tiempo que duró la convicción de la necesidad de un Estado fascista hubo camino compartido entre los liberales provenientes del círculo orteguiano y los que se habían fascistizado más decididamente, es verdad que las siguientes etapas fueron consistiendo en la corrección del camino, a la inversa de lo sucedido antes de la guerra. Por eso me parece importante ver este proceso en lo que tiene de continuidad, sin dejarse seducir más de lo necesario sino analizándolo de manera tranquila, pues se puede poner el acento en una $u$ otra

20 J. Castillejo, Democracias destronadas. Un estudio a la luz de la revolución española 1923-1939, Madrid, Siglo XXI, 2008, p. 28.

21 G. Fraile, “¡La guerra ha terminado!, Ciencia Tomista, año 30, n. 176-177, 1939, pp. 5-16.

22 Madrid, Centro de Estudios Políticos y Constitucionales, 2009. Precedida por un "Estudio preliminar", pp. 17-119.

23 Ibidem, p. 15. fase del pensamiento y de la ejecutoria personal de estos intelectuales. Todas les pertenecen. Lo cierto es que el Instituto y la Revista fueron fundados como el cerebro que ese proceso de legitimación necesitaba y así lo expresa con claridad Juan Gascón ya seis años después de terminada la guerra:

Nunca se insistirá bastante en que el Alzamiento iniciado el 18 de julio de 1936 no fue un pronunciamiento, sino una Cruzada nacional que tendrá como única finalidad rescatar para el porvenir la continuidad del ser de España, en inminente peligro de desaparecer por la conjura de los elementos internacionales y comunistas. Como consecuencia de este origen, el estado surgido de la Revolución nacional no es, en modo alguno, un Estado de dictadura, sino, como repetidamente ha dicho el Caudillo y los hechos han demostrado con harta elocuencia, el régimen actual está sentado en la entraña misma del pueblo español. No es óbice a este calificativo democrático la existencia de unidad de mando, el apiñarse los poderes en manos del Caudillo, fenómeno que si bien se mira es común a todos los pueblos actuales, pues en todos ellos, por sobre las formas tradicionales de su organización política, emerge en definitiva la misma unidad de mando que se resuelve en una figura señera ${ }^{24}$.

No es menos cierto que la revista no se limitó a ser el cerebro, sino que fue, también, el estómago y este se rige por el principio de necesidad como bien había advertido Turró. Sin comprender esta doble función no se entendería el proceso seguido por el Instituto y la evolución que derivó hacia una concepción más centrada en el funcionamiento del Estado y, por consiguiente, en una orientación menos ideológica a lo largo de los sesenta. Desde el crepúsculo de las ideologías se evolucionó hasta del Estado ideal, o dicho, en otros términos, al Estado de razón en la derecha; o hasta la evolución de la filosofía hacia la ciencia (ciencias sociales) en los sectores de la izquierda. En realidad, el Régimen evolucionó por estos dos frentes y nunca mejor dicho. Y ese doble frente convergió, en cierta manera, en una concepción tecnocrática en los ámbitos dominantes del saber y la política, con las excepciones que quieran señalarse. Por su parte, fuera de ese proceso quedaba el integrismo que se mantuvo fiel al tradicionalismo escolástico.

El periodo de legitimación, que aquí comentamos, se centró en tres realidades que eran geográficas, políticas, históricas y simbólicas al mismo tiempo: España, Europa y el que, a partir de 1943, comenzó a dar nombre a una sección de la revista: Mundo hispánico. A veces se trataban por separado, en ocasiones se mostraban interrelacionadas, pero desde un centro constituido por la propia España. Es la ideología propia de una concepción fascista que, si se apoyaba en la Alemania hitleriana y en la Italia mussoliniana, en verdad desde una concepción imperial solo hay espacio para uno. Por eso a Dionisio Ridruejo, durante el periplo de la División Azul, le costó darse cuenta de los designios que la Alemania de Hitler tenía para los países liberados, en expresión de Lanfried, y concretamente la que correspondía a Es-

\footnotetext{
4 J. Gascón Hernández, "Caracteres y funciones de la Presidencia en las Cortes Españolas”, Revista de Estudios Politicos, n. 19-20, 1945, pp. 141-170.
} 
paña: ser un país de "pastores y campesinos". Señala el biógrafo de Ridruejo, Manuel Penella, que el "Doctor Ley era bastante explícito al respecto, cuando decía que España no tendría necesidad de fabricar máquinas de escribir" 25 . Sin embargo, en estos primeros momentos Dionisio Ridruejo, como Serrano Suñer, era "un intervencionista firmísimo porque era un fascista y ambos creían encontrar en las páginas de La España invertebrada la base para definirse como minoría ilustrada capaz de construir el nuevo Estado. Todo ello anterior a la etapa que su biógrafo titula "Una trasmutación decisiva". Algo parecido no dejó de pasarles a los republicanos en la Unión Soviética, como nos cuenta el autor de Los Médicos Republicanos en la Unión Soviética ${ }^{26}$, donde fue a parar Carlos Díez antes citado y que fue de los pocos que consiguió salir a México pues a gran parte de los exiliados se les retuvo el pasaporte. Claro que, por entonces, Ridruejo, que apenas escribió en la Revista de Estudios Políticos, fundador de Escorial, estaba aún por una mayor pureza del falangismo auténtico y, como se sabe, la primera ruptura con el franquismo fue desde estos parámetros; habría que esperar aún para la segunda ruptura que ya respondía a un impulso democrático, tal como detalla Manuel Penella. Es un proceso análogo en varios de los intelectuales que leyeron a Ortega antes de la guerra y que vinieron, de nuevo, a ser liberales en su madurez, bien avanzado el franquismo. Claro es que su propio biógrafo nos señala que en el morral del soldado por tierras rusas llevaba la poesía de Machado y hasta una vida de San Francisco y eso nunca ocurre en balde.

A propósito de cómo va evolucionando la lectura de Ortega sería interesante disponer, para todo este periodo más duro, de un buscador que permitiera comprobar todas las menciones que hay en su obra durante todos estos primeros años de la revista incluida la dedicatoria del texto firmado por Cesar E. Picó que dedica "A D. José Ortega y Gasset" en el n. 18 de $1944^{27}$. Y cómo, incluso, ideas nobles pueden ser convertidas en armas arrojadizas por los totalitarismos.

Desde este esquema puede irse siguiendo la revista de una manera longitudinal, para ir comprobando las inflexiones que se fueron produciendo. En el libro de Sesma Landrín se encuentran bien expuestos los periodos que fueron marcados por los distintos directores, así como los acontecimientos políticos nacionales e internacionales que corrían paralelos a la propia revista. También puede seguirse la trayectoria de las principales firmas: García Valdecasas, Díez del Corral, Antonio Tovar, Corts Grau, Eulogio Palacios, Lissarrague, Eugenio D'Ors, Arboleya, José Antonio Maravall desde luego, Pedro Laín, Fernández Almagro, Menéndez Pidal, Truyol Serra, Julián Marías... Como indica Elías Díaz en el breve epígrafe que a la revista dedica ${ }^{28}$, eran profesionales de casi todos los campos del saber. No olvidemos,

25 M. Penella, Dionisio Ridruejo, poeta y político. Relato de una existencia auténtica, Salamanca, Caja Duero, 1999, p. 235.

26 M. Marco Iguala, Los Médicos Republicanos en la Unión Soviética, Barcelona, Flor del Viento, 2010.

27 C. E. Picó, "Hacia la Hispanidad", con nota preliminar de J.C. Goyeneche, pp. 591-621. La dedicatoria, p. 599.

28 E. Díaz, Pensamiento español... op. cit., pp. 50-58. sin embargo, que la vida, la dura vida, estaba al otro lado de las páginas.

Por mi parte, he hecho un seguimiento de la revista hasta los inicios del 50 cuando ya se habían incorporado García Pelayo, Aranguren y Tierno Galván. Creo que con ellos se inicia una fase distinta. El artículo de este último "Hombre, humanidad y humanismo", publicado en $1950^{29}$ me parece que, con el cambio de década, abre una apuesta más compleja, si no más abierta. "Las semillas del disenso" titula Sesma Landrín, "a este tiempo ${ }^{30}$.

Hay, por supuesto, muchos textos de carácter técnico, sobre cuestiones de derecho administrativo, laboral, etc. pero prima la orientación fuertemente ideológica tanto en los artículos, como en las notas de denso contenido doctrinal y lo mismo dígase de las reseñas. Pues de ahí salieron libros importantes como es conocido y siempre tenían un gran eco en la propia revista.

Sirva, como aproximación, un apunte sobre el tratamiento que, cada una de esas realidades mencionadas, recibió en las distintas secciones de la revista durante la primera década

El tema de España ocupa el primer lugar y el centro. Hablamos de la España recuperada, "forja de un proyecto", según la acertada denominación del propio Nicolás Sesma que habría de llevarse a cabo frente a los grandes enemigos que habían casi conseguido dilapidarla: las naciones demoliberales, el comunismo y, sobre todo, la República que encarnaría todos los males juntos. Ataque, pues, frontal a esos enemigos pero, al tiempo, acarreo de materiales para la reconstrucción, una mezcla de esencialismo no proveniente de la escolástica sino de ese proyecto que se habría interrumpido con la República y que vendría a adobarse con elementos de la historia, no olvidada sino reutilizada: desde el Imperio Romano, pasando por los Reyes Católicos, el compromiso con los Habsburgo, Trento y una singular lectura de la teología de Salamanca (Lissarrague, "Un texto de Francisco de Vitoria sobre la potestad política"31); saltándose el siglo XVIII y el liberalismo del XIX para recuperar la generación de Menéndez Pelayo y la generación de la polémica de la ciencia española por Laín en 1943; la bien conocida lectura del 98 que desembocó en España como problema $^{32}$. Si la historia es la que conforma el carácter. tal como había escrito Ortega, estos intelectuales se aprestaron a probarlo.

En esta búsqueda hacia atrás, no faltó a la cita la figura de Donoso Cortés, estudiado por Gómez Arboleya, traída junto con la de Carl Schmitt, traducido por Francisco Javier Conde, ni la de Balmes sobre quien escribió Corts Grau; e incluso la de Jovellanos, recuperada por la pluma de Giménez Caballero. Las revisiones inteligentes creo que las pusieron Maravall que realizó en 1942 una muy interesa reseña del libro La cultura del Renacimiento en Italia, publicado entonces en Buenos Aires (1941); y Luis Díez Del Corral que ponía las bases doctrinales a partir de su intento de recuperación del doctri-

\footnotetext{
29 N. 52, pp. 181-187.

30 La revista puede consultarse íntegra en https://dialnet.unirioja.es/servlet/revista? codigo $=1166$

N. 2, 1941, pp. 315-325.

32 P. Laín, España como problema, Madrid, Seminario de problemas Hispanoamericanas, 1948.
} 
narismo político, una forma sutil de analizar el tiempo presente. Ya hacia 1946 se recuperó a Costa. "Libertad política, libertad civil según Joaquín Costa" ${ }^{33}$ tituló, entonces, Legaz Lacambra y si Menéndez Pidal había ido incorporando los elementos del "carácter originario de Castilla" desde 1944, con motivo del centenario del nacimiento de Cervantes se incorporó también a nuestro personaje Don Quijote a esta elaboración teórica que hacía de España un Estado histórico a la vez que eterno. El año 1947, centenario del nacimiento de Cervantes, fue un momento propicio para esta recuperación. Finalmente, López Ibor aportaba la fundamentación biológica que el Régimen necesitaba, si bien no publicó demasiado en esta revista.

En esta trayectoria hay un artículo que me parece capital. Me refiero al de García Valdecasas, un largo y denso texto titulado "Los estados totalitarios y el Estado español" publicado en el n. 5 de enero de $1942^{34}$ que pone las bases desde las que interpretar la posición de España en Europa y desde las que fijar la posición del Estado en relación con la sociedad. Las consecuencias las obtiene Jordana Pozas quien, en el mismo número de la revista, publicaba ya la segunda parte de su artículo "El principio de unidad y sus consecuencias políticas y administrativas" ${ }^{35}$ (la primera parte la había publicado en julio de 1941). Su propuesta es la siguiente: "La Unidad que nuestro Movimiento Nacional postula algo completamente distinto a cualquier solución circunstancial. España es. Su ser no es una suma de los elementos que la integran, sino un producto de la historia y un destino que viene llamada a cumplir. Su unidad es de orden espiritual, en cuanto requiere supuestos orgánicos e imponga ciertas normas prácticas de conducta" ${ }^{36}$. Para, un poco más adelante apoyarse en Renan, pero, sobre todo, en Ortega (en Renan se apoya también el propio Ortega) cuando se refiere, en la segunda parte de La rebelión de las masas, al Estado como empresa.

Sin pretender ir más lejos ahora, desde el punto de vista del pensamiento político en la primera década de la revista, sobre todo en los cinco primeros años antes de la derrota del fascismo en Europa, lo más interesante es el resultado de la idea de unidad de este grupo de la Revista de Estudios Políticos. Para ello ahorman materiales de doble procedencia que se catalizan en la filosofía orteguiana: historia y sistema que aquí sirven de fundamento a una teoría totalitaria del Estado que, desde luego, no era la opción de Ortega pero que objetivamente no está claro no lo fuera de alguna parte de los elementos de su propia filosofía. Me remito ahora a quienes apoyaron la República y a quienes terminaron derivando hacia el apoyo al golpe de Estado. Los juicios que sobre el krausismo/institucionismo se han vertido desde la derecha y desde la izquierda frente a las otras filosofías vigentes: neokantismo, positivismo, neoidealismo, etc., en el primer tercio del XX convendría revisarlos a la luz de los acontecimientos históricos.

\footnotetext{
33 M. Fernández Almagro, "El caso de Joaquín Costa", n. 29-30, 1946 , pp. 17-127; L. Legaz Lacambra, "Libertad política y libertad civil según Joaquín Costa”, 29-30, 1946, pp. 1-42.

En fin, esta fue la primera base que luego fue modificándose, primero con la derrota de los fascismos, que hizo suavizar la puntería contra las democracias liberales para centrarse en el anticomunismo, clave para la continuidad del régimen franquista. Es el periodo que Sesma Landrín califica de "fachada liberal" y que dio paso a la que señala como "las semillas del disenso" a partir de 1948 en la que se acentúa una línea más sociológica y orientada hacia las ciencias sociales y políticas en general, como antes indicábamos, al tiempo que la orientación europea se muestra más clara.

Efectivamente, Europa fue la referencia que quedó de manifiesto en el n. 3 cuando García Valdecasas firma su artículo "Relaciones culturales y política exterior"37. Fue ratificado, después, por Antonio de Luna, "España, Europa y la cristiandad" ${ }^{38}$, y por Eduardo Aunós durante el tiempo en que fue Ministro de Justicia, tras su larga experiencia en países europeos y americanos como diplomático, "Las tres columnas de la unidad Europea"39, con una extensión de más de cincuenta páginas. En él sostiene lo siguiente:

La visión española de Europa nos descubre características propias al estudiar la configuración moral y la estructura política del Continente. España quiere siempre para Europa un destino imperial, es decir, una Europa unida cupularmente por la vía del Poder Católico, fusionada en la vida espiritual, esencialmente justa, fundamental y racionalmente justa, o sea, capaz de recoger cuantas empresas brotan dentro de ella con raíz histórica o nacional si son aptas para satisfacer las aspiraciones más altas de los grupos humanos que la habitan y no se oponen a su ansia irrefrenable de universalidad. [...] Es nuestra filosofía, ha sido nuestra acción moral de siglos la que representa nuestro carácter auténtico y nadie con mejor derecho que España puede exhibir sus credenciales ante el mundo europeo, como su más activo y esforzado paladín. [...] Europa debe a los griegos su formación intelectual, a los romanos su estructura imperial y al cristianismo su espiritualidad. Los momentos creadores, cruciales, e su instalación en el mundo, los determinan esas tres fuerzas históricas. Después, compete a los pueblos que la componen dar vida y desarrollo al encargo conferido a esa trilogía básica

a la que dedica cada una de las partes del artículo que termina de la siguiente manera: "De su seno ha de surgir otro gran momento crucial de unidad y triunfo de Europa: el Imperio hispano, pináculo más alto y cupular a que nunca haya llegado el Continente".

Por eso, Pablo Antonio Cuadra había defendido que España había llegado a otra Edad Nueva, "inueva Edad Media!" ${ }^{40}$ y en la crónica de la política nacional Cortázar utilizaba en sus epígrafes expresiones como "la minoría selecta", "España ante el mundo" o "la mirada hacia atrás"! ${ }^{41}$. En general, casi todos los artículos de estos años mantienen un tono similar.

Así pues, la Europa que se preconizaba estos primeros años se inscribía en el fascismo necesario; otro tono

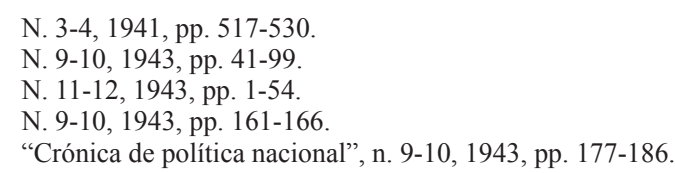


tienen ya los artículos del final de la década, así, el de Julián Marías, "El pensamiento europeo actual y la unidad de Europa"42, y lo mismo puede decirse de los trabajos de Luis Díez del Corral en torno al doctrinarismo político escritos desde 1945.

En general, la retórica sobre Alemania, por lo menos hasta 1943 o 1944, puede suponerse que era muy favorable. Sin embargo, me ha llamado la atención una nota de Nicolás Ramiro que lleva por título "Sobre el sentido de una traducción" 43 (se refiere al libro de Larenz La filosofía contemporánea del Derecho y del Estado, realizada por Galán Gutiérrez y Truyol Serra). El firmante, N. Ramiro, se muestra enormemente crítico con el funcionamiento de la universidad alemana en términos como estos:

los académicos doctores siempre han sido propensos a creer que hay que escribir libros por oficio, téngase o no algo que decir. Se suple la sequedad de pensamiento con distingos que son confusiones de términos y con disquisiciones metodológicas que son suplantaciones o encubrimientos de la carencia de ideas. Se logra así vivir parasitariamente, forjando nuevas versiones o paráfrasis de Kant, Fichte o Hegel, con ayuda de una complicada, oscura y bárbara terminología. Los doctores de sutileza se tornan maestros de oscuridad, cómplices de toda trivialidad ${ }^{44}$.

Casi toda la nota trascurre en este tono muy crítico que recuerda un viejo artículo que Galdós escribió para "La Prensa", el periódico argentino, allá por 1883 cuando afirmaba que en aquel país "solo es permitida una libertad inocente: la filosofía, que, al sentir de muchos, contribuye al adormecimiento nacional y al servilismo de la raza. Llenan las universidades manadas de filósofos, casta insufrible, enemiga de la discreción, del sentido común y de todo concepto claro" 45 .

Al leer en la Revista de Estudios Políticos esta crítica llama la atención la semejanza con los juicios galdosianos, pues, probablemente, el novelista se apoyó en Menéndez Pelayo que ahora era ensalzado como intelectual genuinamente español. Sin embargo, hay una diferencia interesante que merecería ser analizada con mayor detenimiento: mientras el XIX combate el krausismo, este artículo de N. Ramiro lo hace con el neokantismo.

En todo caso es claro que esta concepción de Europa era anacrónica ya en 1945 como tal, y el propio Ridruejo se dio cuenta durante su estancia en Roma, tras su confinamiento y la aceptación de la corresponsalía de Pyresa, pero sólo él comprendió que era necesaria una segunda ruptura que él inició. Y lo hizo tras entrar en contacto con el mundo del exilio. He ahí una clave que nos está costando digerir. La poesía, podría decirse, fue más arriesgada que la filosofía política que optó por la revisión. No se lleva la obra de Machado en balde, decíamos más arriba. Y no porque Dionisio Ridruejo no llegara a ser miembro del Instituto de Estudios Políticos,

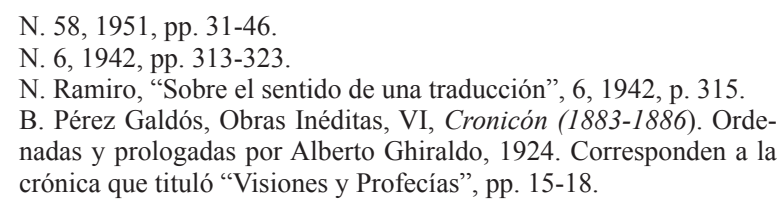

que lo fue, y ahí nació su famoso artículo "Expulsados y comprensivos", publicado en Revista (1952), en este caso la fundada por él como lo había sido Escorial. El juicio que esto merezca queda fuera de las pretensiones de esta aproximación a los primeros años de la Revista de Estudios Políticos. La propuesta de Ridruejo entonces era mucho más avanzada que el doctrinarismo de Díez del Corral. Incluso el artículo de Julián Marías, “El pensamiento europeo actual y la unidad de Europa"46, escrito poco después de la conferencia de Ortega en Berlín, resulta tener bastante menos fuerza que la propuesta de Ortega, que, por otra parte, me parece bastante más lúcida que las realizadas antes de la guerra. En todo caso es interesante leer estos textos junto a los que estaba escribiendo Zambrano en su libro Unamuno ${ }^{47}$ o en los artículos de La agonía de Europa ${ }^{48}$; o lo mismo podríamos decir del libro de Ferrater Mora, escrito en Chile, España y Europa ${ }^{49}$. Hubiera sido precisa una conciliación de diagnósticos por aquellos años. Pero se sabe que no fue posible. El Régimen se mantuvo cambiando de aliados.

"Y es que la Europa a la que ahora volvía a apelarse ya no era la del «nuevo orden» nazi ni tampoco el solar destruido del que hablaba la propaganda franquista, sino la de los planes de integración, la definitiva consolidación democrática en Occidente y el incipiente milagro económico alemán" como señala Ledesma Landrín ${ }^{50}$. Que no fuera posible la democracia entonces no solo condicionó obviamente la vida de España durante treinta años, sino que ha condicionado la construcción de la España democrática actual.

El triángulo de la concepción imperial se cerraba con el vértice constituido por el Mundo Hispánico. Fue esta una sección instaurada en la revista a partir del segundo año de su publicación y que vino a ocupar un lugar muy importante. "Sentido de la hispanidad" titulaba su artículo Salvador Lissarrague en el n. 9 de mayo-junio de 1943 bajo el lema "a solis ortu ad occasum"51. La retórica de estos artículos suena huera cuando se ha leído "Isla de Puerto Rico" que Zambrano había escrito ya tres años antes y no porque ella no utilizara también el término "hispanidad" sino porque lo hacía en un sentido muy diferente. Es sabido que, de la concepción del término "hispanidad" y sus derivados defendida por la Revista de Estudios Políticos, nacieron varias instituciones con las denominaciones de "hispanismo", "hispanidad", etc. Pueden contrastarse aquellas viejas utilizaciones con las nuevas orientaciones recogidas en el libro que ha prologado el profesor de la Universidad de Brown, Julio Ortega, Nuevos hispanismos interdisciplinarios y trasatlánticos ${ }^{52}$ donde mantiene dos ideas muy importantes:

46 Publicado en el n. 58 de 1951, pp. 31-46. Había sido leído en el Seminario del Instituto de Estudios Políticos en el curso 1949-1950.

47 Escrito a comienzos de los años cuarenta, lo tenía ya concebido antes de salir al exilio como tenemos constancia por algunos testimonios epistolares. M. Zambrano, Unamuno, Edición en introducción de M. Gómez Blesa, Barcelona, Debate, 2003.

48 Escritos a lo largo de los años cuarenta. M. Zambrano, La agonía de Europa, ed. de Jesús Moreno, Madrid, Trotta, 2000.

49 Santiago de Chile, Cruz del Sur, 1942.

50 N. Sesma Landrín, op. cit., pp. 102-103.

Pp. 167-173.

Madrid, Iberoamericana, 2010. En buena medida las Jornadas organizadas por la Asociación de Hispanismo Filosófico en la Universidad de Sevilla bajo el título Relatos de cosmopolitismo en el 
primera, que los nuevos hispanismos solo pueden ser plurales, para añadir: "Se sitúan en una contextualización tan cambiante como decisiva, la de una textualidad que consideran en su hechura de modelos de información y cambio" 53 . Y, segunda, que "ningún crítico serio, en español, creería que su labor está exenta de su inserción social, sentido cultural y significación política. Por eso, podemos creer que los estudios trasatlánticos se deben al porvenir" ${ }^{\prime 5}$. Mas esto es el presente y lo traigo a colación para mostrar que no se trata de una cuestión solo del pasado sino, precisamente, del porvenir.

En todo caso, para tener una visión clara de la posición de la Revista de Estudios Políticos he tomado tres muestras muy interesantes: corresponde la primera a Pablo Antonio Cuadra y se titula "Entre la cruz y la espada" 55 . Ahí sostiene el concepto "Cristianoamérica" sobre la idea de que "para que llegara la Cruz hizo falta la espada" y, precisamente, cruzaba esta concepción con la "democracia" pues "estamos levantando del fango de una historia indecente una palabra contaminada con los más sucios crímenes para envolver con ella el cuerpo de Cristo". "Queremos -afirmaba el articulista- hacer de la historia cristiana, escrita por el Espíritu Santo, la historia misma de la Democracia, sucia de actos satánicos y decididamente anticatólica en sus capítulos modernos. En América, sobre todo, existe ya una relación viva y constante -como la relación entre la Celestina y sus falsas doncellas- entre la estafa al pueblo, la persecución al cristiano, el despojo a la Iglesia y esa palabra ahora canonizada. Yo no dudo que podemos redimirla, pero tampoco dudo que mientras no esté redimida, es inicuo para la memoria de los Santos y de los Mártires confundir su historia con esa otra historia tantas veces meretriz" ${ }^{\prime 5}$. Se trata de optar por Cristo frente a Barrabás y por una "América católica", no por una sociedad de provecho sino de una "unidad de destino" y para ello concluye: "Trabajemos. Invitemos a los conquistadores a emprender el camino de la aurora. En espíritu unidos, en espíritu y ansias y lenguas".

Se trata, pues, de un texto perfectamente reconocible, con la retórica propia de una concepción imperial dentro ya de la ortodoxia nacionalcatólica.

Sin embargo, los artículos que firman Fernández Carvajal y Pedro Laín, que pueden considerarse segunda y tercera muestra, son bastante diferentes a la par que interesantes. Se titula el primero "Sobre la personalidad cultural de Hispanoamérica"57; el de Pedro Laín "Extrañeza y entrañeza de España" 58 .

Sostiene Rodrigo Fernández Carvajal que los pueblos de Hispanoamérica son pueblos espectadores de su propio proceso de maduración y lo hace comparando la historia de las naciones europeas, las naciones de Hispanoamérica y Norteamérica. Y lo completa repasando los

pensamiento filosófico hispánico 3-5 abril de 2019 tuvieron que ver con este tema. P. Badillo; C. Hermida; M.A. Pastor; J. Sánchez-Gey; J.M. Sevilla (eds.), Relatos del cosmopolitismo en el Pensamiento Filosófico Hispánico, Madrid, Dickynson, 2021.

3 Ibidem, p. 11.

Ibidem, p. 15.

N. 27-28 de mayo de 1946, pp. 191-210.

Ibidem, p. 195

N. 35-36, septiembre octubre, 1947, pp. 219-229.

N. 29-30, diciembre 1946, pp. 165-172. juicios negativos que los europeos han hecho de América: Schlegel, Maistre, Hegel, Lepardi, Scopenhauer, Papini, etc. frente a los cuales los americanos han elaborados sus apologías. Pero lo interesante que señala Fernández Carvajal es que esa polémica habría superado los ámbitos biológico, político, jurídico, sociológico, el artístico o el literario para alcanzar el nivel de lo filosófico, "con lo que, como dice Arturo Ardao, ha alcanzado la plenitud de su formulación, ya que no se trata tan solo de un ensanchamiento de horizontes, sino de una aprehensión radical del conflicto mismo. Y es notable que este planteamiento de la peculiaridad americana en lo filosófico se hizo de una determinada tendencia del pensamiento europeo contemporáneo: el historicismo de Dilthey. El historicismo ha tratado de reconstruir la evolución ideológica de América" ${ }^{59}$.

Desde este planteamiento se hacen una serie de reflexiones muy finas al hilo de planteamientos como el del uruguayo Zum Felde, El problema de la cultura americana (1943) como una de las expresiones de mayor sinceridad desde lo que denomina "coloniaje cultural latinoamericano" y el drama que esto supone pues -Ortega al fondo- las minorías no calan, se encuentran enterradas "bajo una capa de usos y estilos prefabricados, cuya íntima justificación desconoce, y para cristalizar en formas propias le es necesario romper esa capa...". Después incorpora los juicios sostenidos por la revista chilena Estudios o por el mexicano Samuel Ramos o las Perspectivas sudamericanas de Keyserling ${ }^{60}$.

"En general -sostiene Carvajal- los más inteligentes están conformes en el principio según el cual Hispanoamérica ha de dar, en el futuro, sus propios frutos culturales dentro de una línea occidental, sin que lo indígena sea otra cosa que una matización más o menos intensa o un sustrato étnico informe que ha de ser recogido -aceptando su influjo- en moldes más perfectos" ${ }^{\text {"1 }}$.

En la parte final de su artículo hace una comparativa España-Hispanoamérica-Francia y opta, dentro de la línea conservadora pero lejos de la agresividad retórica del anterior artículo, por sostener que "somos un pueblo trashumante que únicamente acampa y se serena al pie de la más alta montaña. Y cuando el campamento se instala lejos, bajo el cielo libre, hay en él una desazón continua, un brillar de aceros con sangre. Si la personalidad de Hispanoamérica, como la de España, se revisara a esta luz, sería desvanecidos muchos contrasentidos aparentes" $"$.

Laín, por su parte, opta por una aproximación poética, dicho sea en el mejor de los sentidos, en una especie de carta abierta a Juan Carlos Goyeneche, de origen vasco y director de la revista argentina Sol y Luna. En la calidez de la distancia corta, Laín introduce dos términos interesantes: la "hispanofiliación" como superación de la simple hispanofilia y el entrañamiento, solo real cuando se comparte la misma entraña histórica. Lo dice con las siguientes palabras: "Viniste un día Juan Carlos, y nos trajiste el testimonio de nuestra hispanofiliación.

\footnotetext{
R. Fernández Carvajal, op. cit. p. 221.

Pueden leerse estas Perspectivas... en www.cervantesvirtual.com

R. Fernández Carvajal, op.cit., p 225.

Ibidem, p. 229.
} 
Hoy vuelves a la tierra cuya voz caló en el oído de tu abuelo y tienes el compromiso de dar allí el testimonio de la nuestra. Cuenta todo en los verdaderamente hispanofiliales: tu entrañeza y la extrañeza, nuestra insatisfacción y nuestra esperanza, nuestros logros y nuestros proyectos. Dile que los españoles de aquí -por lo menos los que aquí sienten en sus almas esa ambición y ese rigor- les exhortan a ser hispana, humana, cristianamente exigentes de sí mismos. Diles que les necesitamos porque somos españoles y no nacionalistas" ${ }^{63}$. Interesante este final del texto de Pedro Laín que puede merecer diversos juicios pero que resulta razonable a la altura de 1946.

Así pues, si estos textos son una muestra de los muchos publicados en la Revista de Estudios Políticos, podríamos decir que oscilan entre una posición dura, de nacionalcatolicismo y otras, más inteligentes, que dejaban vías abiertas a otras formas de diálogo, siempre desde una posición española o hispana si así quiere definirse.

El primer giro realmente visible de la revista puede decirse que está ya marcado en el artículo de Enrique Tierno Galván, "Hombre, humanidad y humanismo"64 que abría otros que ya pertenecen a Arboleya o a Maravall hacia la mitad de esta segunda década $\mathrm{y}$, por supuesto, a la línea que el propio Tierno impulsaría en la universidad de Salamanca. A su vez, probablemente habría otro cambio de cara en los sesenta, tras los sucesos de 1957, el encuentro de Munich en 1962 y los intentos de búsqueda de una salida democrática que impulsó Ridruejo más que ningún otro.

El interés del artículo de Tierno, escrito al hilo de un comentario al tema tratado en el Congreso de Filosofía de Amsterdam, es mostrar una visión plural del humanismo frente a la visión monolítica que había sido habitual en la línea de la revista en años anteriores. A tres se refería Tierno: al marxista, a los independientes y a los cristianos, así en plural. Más allá del contenido de este breve texto, lo interesante radica en el tono que el mismo tiene, la propuesta a cuatro años de finalizada la segunda gran guerra y la necesidad de superar las "crisis históricas".
Para entonces hacía ya ocho años que Tierno Galván había defendido su tesis "El tacitismo, una contribución al pensamiento político español".

Comenzamos estas páginas aludiendo al protagonismo conferido a la historia en la obra del liberal Galdós. Si el estreno de Electra fue, en su día, un grito a favor de la libertad de conciencia, no dudó nuestro novelista, años después, tras la ficción que para él fue la Restauración canovista, en encomendarse a la diosa Clío y apelar a esa misma conciencia en las palabras finales del Episodio Cánovas a la altura de 1912, para recuperar la verdadera libertad desde el impulso interior de una precursora razón poética. Era el mismo grito que se disolvía en el silencio:

Alarmante es la palabra Revolución. Pero si no inventáis otra menos aterradora, no tendréis más remedio que usarla los que no queráis morir de la honda caquexia que invade el cansado cuerpo de tu Nación. Declaraos revolucionarios, díscolos si os parece mejor esta palabra, contumaces en la rebeldía. En la situación a que llegaréis andando los años, el ideal revolucionario, la actitud indómita si queréis, constituirán el único síntoma de vida. Siga el lenguaje de los bobos llamando paz a lo es realidad es consunción y acabamiento... Sed constantes en la protesta, sedes viriles, románticos, y mientras no venzáis a la muerte, no os ocupéis de "Mariclío". Yo, que ya me siento demasiado clásico, me aburro... y me duermo... ${ }^{65}$.

En la Revista de Estudios Políticos no fue Mariclío la invocada, sino Tácito el recordado por Tierno. Los artículos de José Luis Aranguren, Julián Marías, Tierno Galván y algunos otros, el propio Ridruejo, a la vuelta de diez años de finalizada la guerra civil, trataron de bucear en lo más lúcido de la historia de España y en la apelación a la razón europea como forma de superar la quiebra profunda que había sufrido el liberalismo del que provenía parte de los protagonistas de la revista. Se iniciaba una restauración que habría de ser larga. Con seguridad, la filosofía y la poética, la razón y el grito callado, se necesitan en estas tareas cuando la crisis se torna muy aguda.
P. Laín Entralgo, "Extrañeza...”, op. cit., p. 172.
N. 52, 1950, pp. 181-187.
65 B. Pérez Galdós, Cánovas, F. Sainz de Robles (ed.), O.C., V, Madrid, Aguilar, 1965, p. 585. 


\section{Bibliografía}

Abellán, J. L., Filosofia Española en América (1936-1966), Madrid, Ediciones Guadarrama con Seminario de Ediciones, 1966. Andrés Cobos y otros (eds.), Nuevos Horizontes, Segovia, Imp. De Carlos Martín, 1935.

Badillo, P., C. Hermida, C., M.A. Pastor, M.A., Sánchez-Gey, J. y Sevilla, J.M. (eds.) Relatos del cosmopolitismo en el Pensamiento Filosófico Hispánico, Madrid, Dickynson, 2021.

Castillejo, J., Democracias destronadas. Un estudio a la luz de la revolución española 1923-1939, Madrid, Siglo XXI, 2008, p. 28.

Díaz, E., De la Institución a la Constitución. Política y cultura en la España del siglo XX, Madrid, Trotta, 2009, pp. 49-79.

-, Pensamiento Español en la era de Franco (1939-1975), Madrid, Tecnos, 1992.

Díez Fernández, C., Castidad, Impulso, Deseo, Madrid, Morata, 1930.

Giner, S. y Moreno, L. (eds.), Sociology in Spain, Madrid, CSIC, 1990.

Giner, S., "La reconstrucción cívica de la razón (Reflexiones sobre la interpretación de Elías Díaz en su Pensamiento español en la era de Franco", Revisión de Elías Díaz, sus libros y sus críticos, L. Hierro, F. Laporta, y A. Ruiz Miguel (eds.), Madrid, Centro de Estudios Políticos y Constitucionales, 2007, pp. 157-162.

Laín, P., España como problema, Madrid, Seminario de problemas Hispanoamericanas, 1948.

Marco Iguala, M., Los Médicos Republicanos en la Unión Soviética, Barcelona, Flor del Viento, 2010.

Martín Puerta, A., Ortega y Unamuno en la España de Franco. El debate intelectual durante los años cuarenta y cincuenta, Madrid, Encuentro, 2009, pp. 39-40.

Mora García, J.L., "La recepción del exilio filosófico en España. Una aproximación”, A. Pavón Romero; Ramírez C. I.

Morán, G., El maestro en el erial. Ortega y Gasset y la cultura del franquismo, Barcelona, Tusquets, 1998.

Penella, M., Dionisio Ridruejo, poeta y político. Relato de una existencia auténtica, Salamanca, Caja Duero, 1999 , p. 235.

Pérez Galdós, B., Cánovas, F. Sainz de Robles (ed.), O.C., V, Madrid, Aguilar, 1965, p. 585.

Ramírez González C. I. y Velasco Gómez, A., Estudios y testimonios sobre el exilio español en México. Una visión sobre su presencia en las Humanidades, México, CONACYT, 2016, pp. 129-166.

Sesma Landrín, N., Antología de la "Revista de Estudios Políticos", Madrid, Centro de Estudios Políticos y Constitucionales, 2009.

Zambrano, M., Horizonte del liberalismo. Edición y estudio introductorio a cargo de Jesús Moreno, Madrid, Morata.

-, "María Zambrano: Tres cartas de juventud a Ortega y Gasset", Revista de Occidente, mayo 1991, pp. 7-26. 